\title{
OBJECTIVITY IN SOCIAL RESEARCH: A CRITICAL ANALYSIS
}

Dr Mukesh Kumar Khatwani*

Dr Farida Yasmin Panhwar ${ }^{\dagger}$

\section{Abstract}

This literature review paper discusses the term 'Objectivity' in qualitative research, its importance in social research, and various issues related to establishing objectivity in social research. The paper aims to improve the skills of the novice social researchers and readers. Since more than five decades, the use of qualitative research has been increased in academically developed countries (i.e. USA, UK, Germany, France etc.), and the use of qualitative research in institutions of developing countries has also been witnessed in recent past. Qualitative research explores several areas related to human behaviours and socio-cultural settings/environments. As human behaviours and nature of human interactions are ever changing, hence, the question of objective research arises and makes social research more subjective. Therefore, this study primarily aims to critically analyse the stance of social researchers on objectivity in social research and discuss the possible factors, which may influence qualitative research. Thus, the paper providing the deliberation on objectivity in social research inspires the novice researchers for the development of qualitative research instead of traditional method, deductive, in social research.

Key words: Qualitative research, Objectivity, Subjectivity, Human behaviour, Cultural settings

\footnotetext{
* Director, Area Study Centre, Far East \& Southeast Asia, University of Sindh, Pakistan. Email: mukesh.khatwani@usindh.edu.pk (Corresponding Author)

+ Assistant Professor, Institute of English Language and Literature, University of Sindh, Jamshoro, Pakistan. Email: fareeda.panhwar@usindh.edu.pk
} 


\section{Introduction}

Conventionally, the social, psychological and behavioural sciences used the method of research, which had been employed in natural and life sciences, commonly known as positivist or deductive method of research. August Comte (1798-1857), a French sociologist and father of sociology, terming 'social physics' (later became Sociology) introduces positivist method of research. However, the emergence of a range of social sciences and research in sociology, anthropology and behavioural science posed questions on the appropriateness of deductive method to explore and assess the attitude of human beings and various social and cultural aspects associated to mankind. Because the human nature is ever changing and social and cultural conditions are also ever-changing and they affect human mind. Thus, how could it be possible to not only investigate but understand the socio-cultural, socio-economic and socio-political circumstances/ conditions by employing quantitative method?

Thus, the scholarly discussion by sociologists and anthropologists on the appropriateness of method in social research/sciences gave birth to a new method of inquiry in social research in the early decades of the 20th century. The remarkable contribution on qualitative research by sociologists Park and Burgess (1925) and social anthropologist Mainowski (1925) was witnessed in the 1920s and 1930s. During this period, qualitative data analysis aimed at a more or less objective description of social phenomena in society or in other cultures. The era of 1950 to 1970, which was known as the golden age of qualitative research, had practised modern approach and various ways of coding, for material gathered from respondents through participant observation, were employed to analysis data. The development of the grounded theory (Glaser \& Strauss, 1967) and the attempt in ethnography (Garfinkel, 1967) have commenced the modern qualitative researches (Mohajan, 2018). Development of qualitative research has passed through various phases and qualitative perspectives (philosophical approaches), for example, hermeneutics, 
structuralism, phenomenology and feminism (Mohajan, 2018). This development also raised the question of objectivity in social research and methodological contestation.

Thus, the paper aiming at exploring the issues of establishing objectivity in social research (qualitative) addresses following questions:

1. What objectivity is meant in social research?

2. Is objectivity an absolute truth or a procedure to minimise subjectivity in social research?

3. What are the potential factors associated with researcher and/or research location that affect objectivity of research?

4. How can research avoid/minimise the effect of potential factors?

\section{Numerous Senses or Meanings to Objectivity}

Before discussing the problems of establishing objectivity in the social sciences, first we should understand the term objectivity and its origin and usage in both natural and social sciences. Our usage of the word 'objectivity' (French Objectivite, German Objektivitat) is confused. It refers at once to metaphysics, to methods and to moral (Daston, 1992). The 'objectivity' is not the product of 19th century but it is as old as science itself and even before the Renaissance era objectivity' was mostly used in philosophical literature. From a philosophical point of view, the word 'objectivity' is used to understand the relationship between human mind and nature (God) and how to get enlightenment. The word 'objectivity' is derived from Latin adverbial or adjectival form obiectivus/obiective, introduced by the 14th century Scholastic philosophers such as Duns Scotus and William of Ockham (Daston \& Galison, 2008). After this time, many other philosophers used the term objective/objectivity in their 
philosophical writings; Immanuel Kant gave a new meaning and sense to this term.

In different contexts, whatsoever they may be, objectivity has been meant and understood completely different by different people. Harding (1978) argued that objectivity should not be thought as a property of propositions but, instead, as an attitude towards the condition under which a tested hypothesis regarded as true or false. The researcher possesses some presuppositions regarding the research topic and put these in conclusion, but it must be kept in mind that objectivity requires neutrality and such attitude of researcher, which accepts the results of tested hypothesis. Thus, Novick (1988) shows that objectivity

...is not a single idea, but rather an extensive collection of assumptions, attitudes, aspirations and antipathies. At best it is what the philosopher W. B. Gallie has called an "essentially contested concept", like "social justice" or "leading a Christian life", the exact meaning of which will always be in dispute (as cited in Harding, 1995, p. 333).

For last two centuries, the term is used as practice and ambition; as practice, it delineated the procedure ensuring valid research findings and as ambition, it drew an epistemological trajectory by which the social and humanistic disciplines might prove worthy in comparison to physical science (Natter, Schatzkiv \& Johnes, 1995). Three modes of objectivity are used in theology, philosophy and science: Firstly, prime focus of objectivity is on processes such as scientific experimentation or human interactions; in particular, these processes attempt to directly "get at objects" in the world. Secondly, it focuses on processes of thoughts or processes of reasoning. Thirdly, social processes that structure epistemically important procedures, and examines in particular, ways to reach agreement through these processes (Douglas, 2004). Thus, from the above discussion it can be concluded that objectivity is a mode, a procedure, and a systematic 
set of techniques which dissociate objective judgements from any essential connection with the opinions and experiences of persons, or from anything that can be called 'oneself' (Newell, 1986).

\section{Objectivity in Social Sciences}

Objectivity is believed to be the most universal trait of the sciences, which differentiates them from unscientific points of view. Simply, objectivity, means the elimination of all subjectivity, is not limited to science alone; but it is an attitude towards life which one can assume also in practical affairs (Bollnow, 1974). Objectivity is pre-eminently the basic attitude of the scientist. Therefore, the enquiry of the objectivity is actually is the question of the methodological guarantee of a science. Since the rise of modern natural sciences, the criterion of such objectivity has been universal validation. There are two traits which guarantee universal validation; ability to repeat experiments and second one is the reduction, the measurable (Bollnow, 1974).

Sociological research has always emphasized on the establishment of objectivity. For example, renowned sociologist Emile Durkheim in his book Rules of the Sociological Method stated that social facts must be treated as things and all preconceived notions about social facts must be abandoned (Durkheim, 1895 as cited in Jones, 1986). Similarly, Max Weber's emphasis on 'sociology must be value free' indicates the significance of objectivity in social or sociological research (Sharlin, 1974). Social scientists also seek to establish the same 'universal validation', which is used by natural scientists, but it is not as easy for them as for the natural scientists is. Because natural sciences study 'objects', which are not dynamic while social sciences study human mind, actions and behaviours, which are ever changing and not universal. We cannot reduce human mind to object experiment. Therefore, the universal validation cannot be attained (Bollnow, 1974) in social sciences.

The difficulty with the humanities/social sciences is that the subjectivity of the knower/researcher cannot be eliminated because of 
the many factors such as researcher's feelings, emotions, cultural values and sympathies with observed community/group. Emergence of various theories and approaches in social sciences provided a wider space for the discussion and debate over 'objectivity' in social sciences and various schools of thought came with their different conclusions. Karl Marx criticized 'objectivity' very much and labelled it as the tool of ruling and capitalist class and in the name of objectivity most of social scientists have served the interest of ruling and capitalist class. He says 'the ideas of the ruling class in every epoch are the ruling idea' (Railton, 1991). Sociologists of the women's liberation movements and black militant sociologists proposed the idea that nothing can take the place of first-hand experience: only women can understand women's problems and only blacks can understand blacks (Agassi, 1974).

Max Weber tried to resolve the conflict of methodology in social sciences. He was of the opinion that it is impossible for social scientist to be total objective but what a social scientist can do, is to follow the same procedure of natural sciences, so that the study could be made reliable and justifiable. He emphasised on 'ideal types' whereby a social scientist declares all his/her assumptions before embarking on a research (Morris, n.d). Weber does say that there is no objective analysis "independent of special and 'one-sided' viewpoints," a remark that does not rule out objectivity, only objectivity prior to a perspective. One of the "deadly sins in the area of politics" is, Weber says, "a lack of objectivity." (Hoenisch, 2006).

\section{Objectivity as a Procedure}

Most of the social scientists are of the opinion that 'objectivity', in social sciences or in natural sciences, is not a truth (fact) but it is a procedure or a set of the techniques which help researchers to minimise the subjectivity and make the research studies more rationale and neutral. It is believed that science provides us with a view of the world that is objective in two, seemingly, quite different 
senses of that term (Longino, 1990). In the first sense, objectivity is all about truth and scientific realism and in the second sense objectivity is taken as mode or procedure of inquiry. As per the first sense of objectivity, it is impossible to establish objectivity in social science but as per the second sense the effort could be made to make the social enquiry 'objective', if not complete. Social sciences are opposite to natural sciences not only in the terms of empirical subject matter but also in the terms of basic method and mode of conceptualization. Thus, it is better for social researchers to take 'objectivity' in the second sense (mode of enquiry) while conducting their research, which keeps researchers away from their personal values, feelings and also keeps research less biased.

\section{Factors Affecting Objectivity in Social Research}

Most of social scientists agree upon that complete objectivity in social studies /research is, of course, impossible but they also emphasise that it does not mean that a researcher go away from the scientific methods of research and present his /her own results. He/she has to follow the set of various existing methods of research which minimise the subjectivity and help to find out the neutral results which could also be acceptable to the other researchers. Thus, objectivity is such a concept which may not completely but somehow binds the social researcher to be 'objective' in his/her studies. We have identified some major problems, which undermine objectivity in social science, are; researcher's interest in selection of topic; researcher's self-interest, self-experience and cultural values; observed community/group's cultural values; researcher's compassion with observed community; researcher's faculty of perception, observation and interpretation; having no peculiar method of research in social science; problem of tainted and insufficient evidence; and problem of neutral assessment of data. These identified problems are discussed in below sections of the paper. 


\section{Researcher's Interest in Selection of Research Topic}

The first and the foremost obstacle or problem to establish objectivity in social science is researcher's particular involvement in topic of choice that relates to both his/her research interest and emotional make-up (Agassi 1974). On what grounds did the researcher choose his/her research topic? Is there any cultural, religious or ethnical similarity between the observing community and the community of investigator? What degree of researcher's attachment is with that observing community? These questions are common in social research and are directly related to investigator's personal wishes and feelings. For example, a researcher, who is physically disabled, conducts research to know the socio-economic problems of the disabled persons. Is it possible for that researcher to be 'objective' in his/her research study? Does researcher keep control over his/her personal emotions and experience being a disabled person? Obviously, it could be hard, if not impossible, for keeping his/her feelings, emotions and experiences aside. Surely, he/she considers the problems of the disabled as his/her own and does favour to the group (disabled persons) of which he/she belongs to. It is mostly believed in social sciences that selection of topic for research is based on subjectivity, thus the results could not be objective. However, choice of research topic cannot be free from personal preferences/interests and ideological biases of the researcher. Similarly, Gunnar Myrdal (1969) warns that entire objectivity in social research is an illusion, which can never be accomplished because certain viewpoints guide altogether research and viewpoints involve subjectivity.

\section{Researcher's Cultural Beliefs and Values}

It is, of course, true that complete objectivity in social inquiry is an impossibility, but accomplishing as much of it as reasonably possible, is a mandatory for a scientific inquiry. It is widely believed that researcher's values affect research. To avoid this one should follow scientific values, however; according to epistemological relativism, 
scientific values are just values and are unable to protect researcher from others values and they do not deserve special privilege (Natter, et al, 1995). Furthermore, the man is social animal and lives in a particular group. He/she possesses cultural traditions, values, mores, religious beliefs etc. being a member of particular group. He /she has a strong attachment/involvement with these traditions and values and he/she also considers these traditions superior to all others throughout the world. This natural tendency of human being impels investigators to put personal feelings in their research. Every human has some intellectual preferences and standpoint (Agassi, 1974) which affect objectivity in social research. The prejudices resulting from politico-ideological convictions are, of course, commonplace. Politico-ideological convictions play a significant role in distorting social realities. It is a commonplace that personal economic selfinterest or the economic interest of the scientist's group may bias his judgment (Agassi, 1974). It is not possible for research to withdraw value judgements from scientific discussion; therefore, valuejudgements are 'subjective' in origin (Weber, 1904).

Objectivity may be an impossible ideal, but along the way of seeking objectivity one may become less subjective. To seek objectivity (or a lessening of subjectivity) researchers must compensate for their own subjective experiences. They should compensate for what they've been subjected to. If one encounters a white person who hates blacks, he must accept that this doesn't mean all white people hate black people. Thus, it is crucial that researcher must detach himself/herself from cultural values, beliefs, presuppositions and personal bad experiences to make results of the study more objective and bias free.

\section{Observed Community's Cultural Values and Beliefs}

It is believed that cultural values and beliefs are deeply rooted and that particular community has a strong attachment with these cultural values and beliefs, and that strong attachment gives birth to 'ethnocentrism' (one's own cultural values and beliefs are superior to 
all others). Thus, cultural values and beliefs of researcher and researched community affect objectivity in social science. All knowledge of cultural reality, as may be seen, is always knowledge from particular points of view (Weber, 1904), but the key requirement for maintaining objectivity in research study, is that the social scientists must abandon or transcend his ethnocentric and egocentric biases while carrying out researches. When social scientists study the social issues then they would have to deal with sensation, emotion and values of that particular community, of course, which are subjective, so it is not only difficult but impossible to be objective about the subjective matters. As the cultural values and beliefs are not universal but vary from society to society, community to community and group to group, this variation of meaning and sense of cultural values and beliefs create hurdles for researcher to understand the proper meaning and sense of these cultural traditions and values of observed community (Khatwani, 2016, 2017). Here most of the researchers observe cultural values and traditions of observed community in the context of their own cultural values and traditions, which further lessens the objectivity.

\section{Researcher's Compassion and Consideration to the Observing Community}

Our very human, social, and historical ability to comprehend, to understand, and to interpret is important hurdle in establishing objectivity in social research (Wazibort, 2004). Human nature of very social and having feelings of sympathy with his/her own group, community, ethnicity and religion do affect the objectivity in social enquiry. For example, the emergence of criticism on 'objectivity' and the conclusions of social scientists that white sociologists cannot objectively study the black people, richer scientists cannot study more objectively about the problems of poor community, men social scientists could not be bias free when they conduct research on social problems of women. Feminism, which actually is a political movement for women's actual rights and privilege, has become a 
feminist approach to science. Feminist social scientists are of the opinion that research projects in the social sciences have often ignored women and they suggest feminist approach to science (research). As Feminist research aims to empower women, therefore; feminist epistemologies accept women's experiences thought their live stories/histories as legitimate sources of knowledge (Campbell \& Wasco, 2000). Can a research on the violence against women conducted by a woman researcher through applying feminists approach be objective and bias free? Could the research based on the stories be objective and scientific? Could these stories absolutely be true? Here the researcher cannot control over her own emotional feelings, sympathies as well as emotional feelings of observing group/community. Feminist approach to science, criticise certain scientific claims for reflecting bias and suggest that feminist approach to science produce objective results of research. This claim of feminist approach makes itself biased and unscientific.

\section{Researcher's Observation and Interpretation in Personal Cultural Context}

Observation, perception and interpretation are of crucial significance in social research and the ability of researcher to observe, perceive and interpret the phenomenon also maximises or minimises the objectivity. Observation is a technique in social research to receive knowledge of the outside world through senses or record data by using scientific instrument. It could be a particular way we look at things or something. Observation plays important role in testing hypothesis and coming to conclusion with data gathered in research. 'Scientific observation is always aimed at making sense of information that exists independently of our beliefs', and this non-epistemic information is the input from non-epistemic perception (Moser, 1988). It is also believed that personal traits affect scientific observation. The assumption that social inquiry is scientific if proper techniques of observation and record (preferably statistical) are employed (Dewey, 1938). But again the problem is researcher observes in context of his 
or her cultural background and he or she hardly can avoid that. Harlod Brown's causal theory of perception emphasizes on scientific observation for the objectivity. He presents two necessary conditions, 'relevance' and 'independence' of scientific objectivity (Moser, 1988). Interpretation is the process through which raw data is analysed, providing the answers to the research question. Now interpretation of data depends on the availability of sufficient data and interpretative faculty or capability of researcher. The concept of perception is of interest here as a basic, central example of a causal concept. Understanding perception is necessary for grasping the idea of objectivity

\section{No Peculiar Method of Research in Social Sciences}

Contrast to natural sciences there is no peculiar method for conducting research in social sciences because natural scientists deal with 'objects' while social scientists deal with 'human actions, behaviour and their social problems'. In the early phase of evolution of social sciences, it was emphasized that social scientists must apply the method [quantitative]) which is, used by the natural scientists in their studies, but with the development of social sciences, debate started among social scientists on the method of research in social science and various methods and approaches were suggested by social scientists. The problem of heterogeneous (Bisbee, 1937) material also minimises objectivity in social science.

\section{Problem of Tainted and Insufficient Evidence}

Marks Ross (1978) in his article 'Who Is Listening the Myth?' presents three major obstacles in establishing objectivity in social sciences, one of them is 'tainted evidence'. Given the evident success of modern science it is understandable that scientific knowledge has become the paradigm of objective knowledge. Significantly, it is with respect to scientific knowledge that the problems of objectivity have been most extensively discussed in recent years. 
In any research reliability of data/evidence is significant and without which the research cannot be objective or bias free. As the subject matter of social science is human behaviour/action, their interaction and interrelationships, and ways and meanings of that interaction, interrelationship and intercommunication vary from society to society, from one cultural environment to another, and very interesting that the nature of human being is ever-changing. Thus, the evidence/data collected form group of person, community could not be accurate or reliable. It is strongly believed in science that the magnificence or credibility of scientific enquiry/ study based on empirical method. Set hypothesis is tested on the result of observation and experiments drawn from the collected data and 'facts' are what they are, whether investigators like or not. Here the investigator's observation and interpretation play important role. Unfortunately, when we study the social issues we ourselves develop a notion/myth about these social issues. This notion is not just developed in investigator's mind but is product of society from generation to generations and we believe that notion as truth, this attitude also makes our study less objective or subjective. We take 'facts' of any matter as more reflection of how we see things than what they are in themselves (Ross, 1978).

The problem of tainted evidence mostly arises in social research; while there is a popular notion/conception in science that hypothesis is assessed/tested on gathered facts. Thus, if the gathered evidences are tainted then definitely the research could not be considered objective. Further, the researcher's ability of observation, perception and interpretation do affect the results and here the personal involvement of researcher is hardly to be avoided. Therefore, it is believed, our evidence is tainted, and affected by the subjective elements.

It is common that researchers gather more information for any investigation to make their conclusions or results more likely to be correct and objective. But the problem arises is that huge information 
alter in their conclusions or results. Thus, the more collected information gives various conclusions and even sometime totally different from the previous ones. This makes the investigator confused and simultaneously reduces objectivity. For establishing objectivity, we need sufficient evidence and their question arises that how can we be sure that have a sufficient evidence on which to base our conclusion (Ross, 1978).

\section{Problem of Assessment of Evidence}

Besides the problems of tainted evidence and insufficient evidence, the assessment of evidence / data further reduces objectivity in social research. There is no a neutral set of standards for assessing explanations (Ross, 1978). Therefore, it is difficult for investigators of social sciences to give what significance to which particular bunch of evidence. Different people accept different explanations and definitions of the same terms in social sciences, which again create problems in proper assessment of evidence and explanation of theory and terms. Marks Rose raising the problems of assessment writes;

the Copernican controversy has certainly taught us that we must be prepared to call into question our standards of assessment; the Aristotelians had to learn that the Philosopher (Aristotle) did not know as much about mechanics or astronomy as they thought he did, and the theologians had to learn that it is dangerous move to seek confirmation for a scientific theory in the Bible. Experience with the quantum theory should have taught us not to place too much emphasis on preoccupied ideas of nature's simplicity, and the advent of relativity theory should teach us that even a highly successful theory (Newton's) can be improved upon (Moser, 1988, p. 556).

From the above paragraph it is obvious that change or improvement is a continuous process in research and there is not ultimate truth in research. It also proves that 'objectivity' is not a truth but a set of technique (procedure) of research which helps in making research more reliable, justifiable and verifiable. 


\section{Conclusion}

Complete objectivity continues to be an elusive goal in social sciences. But what a research can do is to keep the above discussed problems of objectivity in his/her mind and take objectivity not as truth but as a set of the techniques, which makes results more objective and lessens the subjectivity. Authors suggest that a researcher should make his/her value preference clear in research project and result obtained from one method should be cross-checked with those from the other. Field limitations must be clearly stated in the research project. Thus, paper concludes that a social researcher, applying the technique of reflexivity on over all process of research and protocol of research, should attempt to achieve objectivity as much as reasonably possible in his/her research.

\section{References}

Agassi, J. B. (1974). Objectivity in the social sciences. In R. J. Seeger and R. S. Cohen (Eds.) Philosophical Foundations of Science (pp.305-316). Dordrecht, Holland: Springer

Bisbee, E. (1937). Objectivity in social sciences. Philosophy of Science, 4(3), 371382

Bollnow, O. F. (1974). The objectivity of the humanities and the essence of truth. Philosophy Today, 18(4), 3-18

Campbell, R., and Wasco, S. M. (2000). Feminist approaches to social science: Epistemological and methodological tenets. American Journal of Community Psychology, 28, 771-791

Daston, L. (1992). Objectivity and the escape from perspective. Social Studies of Science, 22(4), 597-618

Daston, L., and Galison, P. (2008). Objectivity. New York: Zone Books

Dewey, J. (2003). Social Inquiry. In G. Delanty, and P. Strydom (Eds.), Philosophies of social science: The classic and contemporary readings (pp. 290-299). Maidenhead: Open University Press 
Douglas, H. (2004). The irreducible complexity of objectivity. Synthese, 138(3) Retrieved from http://www.jstor.org.ezproxy.sussex.ac.uk /stable/pdfplus/20118400.pdf

Garfinkel, H. (1967). Studies in ethnomethodology. Englewood Cliffs, NJ: Prentice Hall

Glaser, B. G., and Strauss, A.L. (1967). The discovery of grounded theory: Strategies for qualitative research. Chicago: Aldine Publishing Company

Harding, S. G. (1995). Strong Objectivity: A response to the new objectivity Question. Synthese, 104, 331-349, Retrieved from: http://philpapers.org/rec/HARSOA

Harding, S. G. (1978). Four contributions values can make to the objectivity of Social Science. Proceedings of the Biennial Meeting of the Philosophy of Science Association, 199-209

Hoenisch, S. (2006). Max Weber's view of objectivity in social science. Available from: www.Criticism.com

Jones, R. A. (1986). Emile Durkheim: An introduction to four major works. Beverly Hills, CA: Sage Publications, Inc. Available from: http://durkheim.uchicago.edu/Summaries/rules.html

Khatwani, M.K. (2017). Professional women's experience of autonomy and independence in Sindh-Pakistan, In A., Alvinius (Ed.) Gender differences in different contexts (pp. 93-116). Croatia: Intech Open

Khatwani, M. K. (2016). Professional women's perceptions \& experiences of respectability, social status, and autonomy: A case study of women employed at the University of Sindh, Jamshoro-Pakistan. [PhD Thesis], School of Law, Politics and Sociology, University of Sussex.

Longino, H. E. (1990). Science as social knowledge. New Jersey: Princeton University Press

Mainowski, B. (1925). Argonauts of the western pacific: An account of native enterprise and adventure in the archipelagos of Melanesian New Guinea. New York: Datton 
Mohajan, H. (2018). Qualitative research methodology in social sciences and related subjects. Journal of Economic Development, Environment and People, 7(1), 23-48

Moser, P. K. (1988). Observation and objectivity. British Journal of Philosophy of Science, 39(4), 551-561

Morris, S. (n.d). Did Weber think that social science could be 'objective'? In Paper-1 History and Theories of Social Science, Christ College. Retrieved from: http://www.stewartmorris.com/essays/01Ingham4.pdf

Myrdal, G. (1969). Objectivity in social research. New York: Pantheon.

Natter, W., Schatzki, T. R., and Johnes, J. P. (Eds.) (1995). Objectivity and its others. New York: The Guilford Press

Newell, R.W. (1986). Objectivity, empiricism and truth. London: Routledge \& K. Paul

Novick, P (1988). The noble dream: The objectivity and American historical profession. Cambridge University Press

Park, R., and Burgess, E. (1925). The city: Suggestions for the investigation of human behavior in the urban environment. Chicago: University of Chicago Press

Railton, P. (1991). Marx and the objectivity of science. In R. Boyd, P. Gasper, Philip, and J. D. Trout (Eds.) The philosophy of science (pp. 763-773). London: Massachusetts Institute of Technology

Ross. M. (1978). The problem of tainted evidence -The problem of insufficient evidence- the problem of assessment-who is telling the myth? In P. Helm (Ed.) Objective knowledge: A Christian perspective (pp. 131-146). Leicester: Inter-Varsity Press

Sharlin, A. (1974). Max Weber and the origins of the idea of value-free social science. European Journal of Sociology, 15(2), 337-353. Retrieved from www.jstor.org/stable/23998534

Wazibort, R. (2004). Objectivity in social science: Toward a hermeneutical evolutionary theory. Philosophy of the Social Sciences, 34(1), 151-162

Weber, M. (2003). Objectivity in social science. In G. Delanty, and P. Strydom (Eds.) Philosophies of Social Science: The classical and contemporary readings (pp.107-120). Maidenhead: Open University Press 